Bundesgesundheitsbl 2016 $\cdot 59: 113-123$

DOI 10.1007/s00103-015-2261-z

Online publiziert: 7. Oktober 2015

(c) Springer-Verlag Berlin Heidelberg 2015

CrossMark

Evgeny A. Idelevich ${ }^{1}$ Christian Lanckohr ${ }^{2}$. Dagmar Horn ${ }^{3}$. Lothar H. Wieler ${ }^{4,5,6}$. Karsten Becker ${ }^{1} \cdot$ Robin Köck ${ }^{1,6}$

${ }^{1}$ Institut für Medizinische Mikrobiologie, Universitätsklinikum Münster, Münster, Deutschland

${ }^{2}$ Klinik für Anästhesiologie, operative Intensivmedizin und Schmerztherapie, Universitätsklinikum Münster, Münster, Deutschland

${ }^{3}$ Apotheke, Universitätsklinikum Münster, Münster, Deutschland

${ }^{4}$ Robert Koch-Institut, Berlin, Deutschland

${ }^{5}$ Institut für Mikrobiologie und Tierseuchen, Freie Universität Berlin, Berlin, Deutschland

${ }^{6}$ Fachgruppe Zoonosen, Deutschen Gesellschaft für Hygiene und Mikrobiologie (DGHM), Münster, Deutschland

\title{
Antibiotika-resistente Erreger in Deutschland
}

\section{Die Rolle von nicht nosokomialen Ansteckungsquellen}

In den vergangenen Jahren hat sich in Deutschland die Antibiotikaempfindlichkeit von bakteriellen Erregern deutlich verändert. Insbesondere haben bei Enterobakterien (z. B. Escherichia coli, Klebsiella spp.) durch die Bildung von Beta-Lactamasen mit ausgedehntem Wirkungsspektrum (engl. Extended-Spectrum Beta-Lactamases, ESBL) bedingte Resistenzen gegenüber Cephalosporinen der dritten Generation zugenommen. Im Jahr 2013 waren 12,2 \% der E. coli- und $14,9 \%$ der K. pneumoniae-Isolate aus klinischen Untersuchungsmaterialien Cefotaxim-resistent; $8,8 \%$ der E. coliund $10,8 \%$ der K. pneumoniae-Isolate erfüllten dabei die Multiresistenzdefinition „3MRGN“ (Daten: Robert Koch-Institut; https://ars.rki, stationäre Versorgung, Datenstand 18.04.2015) [1]. Eineneue, zunehmend relevante Gefahr auch für Deutschland stellen Carbapenemase-bildende Enterobakterien (CRE) dar [2].

Die Verbreitungsdynamik von Antibiotikaresistenzen ist abhängig vom „ökologischen" Zusammenspiel zwischen Selektionsdruck (durch Antibiotika, aber auch andere Substanzen wie Metalle oder Desinfektionsmittel) im Wirt oder Reservoir, von Möglichkeiten zur (in)direkten Übertragung, von der ResistenzgenExpression und dem De-novo-Erwerb von Resistenzeigenschaften [3, 4]. Diese
Grundprinzipien der Verbreitung von Erregern mit Multiresistenzen (MRE) gelten gleichsam in der Human- und der Veterinärmedizin.

In den letzten Jahren ist der Aspekt der potenziellen zoonotischen Übertragung von MRE zwischen Tier und Mensch zunehmend in den Focus gerückt, da insbesondere bei landwirtschaftlichen Nutztieren vermehrt Methicillin-resistente Staphylococcus aureus (MRSA) und ESBLbildende Enterobakterien (ESBL-E) nachgewiesen wurden. In der öffentlichen Diskussion wird seitdem die Frage gestellt, inwieweit Tiere die Quelle für MRE-Kolonisationen oder - Infektionen beim Menschen sein können, z. B. durch direkten Tierkontakt, Lebensmittel tierischen Ursprungs, Abluft aus Tierställen oder Gülle.

Diese Frage ist auch vor dem Hintergrund der Bemühungen um eine rationale Antibiotikagabe in der Humanmedizin von Bedeutung, da der potenzielle Erfolg von „Antibiotic-Stewardship“(ABS)- Ansätzen (neben der Berücksichtigung lokaler Resistenzdaten) auch vom Vorkommen von MRE außerhalb von Gesundheitseinrichtungen abhängt. Für die Arbeit von interdisziplinären ABS-Teams ist es deshalb wichtig, neben dem Wissen um nosokomiale Ansteckungsquellen für MRE auch einen Überblick über zoonotische Quellen für MRE zu haben.
Diese Übersichtsarbeit trägt deshalb Daten zum Vorkommen von MRSA und ESBL-E (sowie CRE) bei Mensch und Tier in Deutschland sowie damit assoziierte Risikofaktoren zusammen und diskutiert die Ergebnisse im Hinblick auf die Fragen, welche Rolle Übertragungen vom Tier auf den Menschen hierbei tatsächlich spielen und welche Präventionsmaßnahmen geeignet sind, um Übertragungen und Infektionen des Menschen durch MRE vorzubeugen.

\section{Methodik}

Eine Literaturrecherche erfolgte in PubMed (Suchbegriffe: Germany AND [MRSA OR ESBL OR carbapenemase]) unter Beschränkung des Publikationszeitraums (1.1.2010 bis 31.12.2014). Relevante Literatur wurde durch Screening von Überschriften und Abstracts identifiziert und ergänzt (sofern wenig Literatur in PubMed verfügbar) durch Publikationen von Infektionsschutzbehörden bzw. die dort zitierten Originalarbeiten. Auswahlkriterium war, dass die Arbeiten Informationen $\mathrm{zu}$ folgenden Fragestellungen boten:

1. Welche Daten zur Prävalenz von MRSA, ESBL-E und CRE beim Tier und beim Menschen liegen für Deutschland vor? 


\section{Originalien und Übersichten}

\begin{tabular}{|c|c|c|c|}
\hline $\begin{array}{l}\text { Region, Studie Jahr der } \\
\text { Untersuchung }\end{array}$ & Untersuchungssetting & Anzahl Untersuchte & $\begin{array}{l}\text { Erreger: Prävalenz (Spezies und ESBL-Resistenzge- } \\
\text { ne, sofern getestet) }\end{array}$ \\
\hline $\begin{array}{l}\text { Frankfurt, Gruber et al. [9], } \\
2006 / 2007\end{array}$ & $\begin{array}{l}2 \text { geriatrische Krankenhäuser, } 8 \\
\text { Altenheime, } 2 \text { ambulante Pflegeein- } \\
\text { richtungen }\end{array}$ & $\begin{array}{l}288 \text { (Patienten), } \\
64 \text { (Personal) }\end{array}$ & $\begin{array}{l}\text { ESBL-E: 8,7\% (Patienten), 3,1 \% (Personal) davon } 89 \% \\
\text { ESBL-E. coli (CTX-M-15 88\%, CTX-M-1, CTX-M-14, TEM- } \\
52 \text { je 4\%), } 11 \% \text { ESBL-K. pneumoniae }\end{array}$ \\
\hline $\begin{array}{l}\text { Hessen, Arvand et al. [17], } \\
\text { 2010/2011 }\end{array}$ & 11 Altenheime & 240 & $\begin{array}{l}\text { ESBL-E: 9,6\% davon } 96 \% \text { E. coli (CTX-M-15 63\%, } \\
\text { CTX-M-1 21\%) und 4\% ESBL-K. pneumoniae }\end{array}$ \\
\hline $\begin{array}{l}\text { Deutschlandweit, Vehre- } \\
\text { schild et al. [16], 2011/2012 }\end{array}$ & 5 Krankenhäuser (Hämatoonkologie) & 497 & $\begin{array}{l}\text { ESBL-E: } 11 \% \text { davon } 83 \% \text { E. coli, } 15 \% \text { K. pneumoniae, je } \\
1 \% \text { K. oxytoca und E. cloacae }\end{array}$ \\
\hline $\begin{array}{l}\text { Frankfurt, Heudorf et al. [10], } \\
2012\end{array}$ & 8 Langzeitpflegeeinrichtungen & 150 & $\begin{array}{l}\text { ESBL-Ea: } 26,7 \% \text { davon } 75 \% \text { E. coli, } 15 \% \text { K. pneumoniae, } \\
5 \% \text { E. cloacae, je } 2,5 \% \text { K. oxytoca, K. ascorbata }\end{array}$ \\
\hline $\begin{array}{l}\text { Sachsen, Ehrhard et al. [15], } \\
\text { 2012/2013 }\end{array}$ & $\begin{array}{l}53 \text { Krankenhäuser (meist Intensiv- } \\
\text { stationen) }\end{array}$ & 1037 & $\begin{array}{l}\text { ESBL-E: } 16 \% \text { davon } 63 \% \text { ESBL-E. coli, } 30 \% \text { K. pneumoni- } \\
\text { ae, } 3 \% \text { K. oxytoca, } 4 \% \text { andere Enterobakterien }\end{array}$ \\
\hline $\begin{array}{l}\text { Bayern, Valenza et al. [11], } \\
\text { 2009-2012 }\end{array}$ & Allgemeinbevölkerung & 3344 & $\begin{array}{l}\text { ESBL-E. coli: 6,3\% (CTX-M-15 46\%, CTX-M-1 24\%, } \\
\text { CTX-M-14 15\%) }\end{array}$ \\
\hline $\begin{array}{l}\text { Hamburg, Belmar Campos et } \\
\text { al. [12], } 2011\end{array}$ & $\begin{array}{l}\text { Allgemeinbevölkerung (Kranken- } \\
\text { hausambulanz) }\end{array}$ & 707 & $\begin{array}{l}\text { ESBL-E: 4,1 \% davon } 100 \% \text { E. coli (CTX M-15 38\%, } \\
\text { CTX-M-14 17\%, CTX-M-1 17\%, CTX-M-27 7\%, CTX-M-9, } \\
\text { CTX-M-8, CTX-M-55, SHV-2, SHV-12, TEM-52 alle 3\%) }\end{array}$ \\
\hline $\begin{array}{l}\text { Deutschland/Österreich, } \\
\text { Meyer et al. [13]; } 2011\end{array}$ & $\begin{array}{l}\text { Allgemeinbevölkerung (Ärzte und } \\
\text { Hygienefachpflegekräfte während } \\
\text { einer Tagung) }\end{array}$ & 231 & ESBL-E: $3,5 \%$ davon $100 \%$ E. coli \\
\hline $\begin{array}{l}\text { Leipzig, Lübbert et al. [14]; } \\
2013\end{array}$ & $\begin{array}{l}\text { Allgemeinbevölkerung (Reisemedizi- } \\
\text { nische Sprechstunde vor Reise) }\end{array}$ & 205 & $\begin{array}{l}\text { ESBL-E: 6,8\% davon } 100 \% \text { E. coli (CTX-M-15 29\%, } \\
\text { CTX-M-1 und CTX-M-55 je } 21 \% \text {, CTX-M-14 14\%, } \\
\text { CTX-M-9 und CTX-M-27 je 7\%) }\end{array}$ \\
\hline
\end{tabular}

2. Welche Risikofaktoren sind mit dem Vorkommen von MRSA, ESBL-E und CRE beim Menschen assoziiert (unter besonderer Berücksichtigung des Kenntnisstandes zu zoonotischen, nicht nosokomialen Übertragungen)?

\section{Ergebnisse}

\section{Prävalenz beim Menschen}

In Deutschland sind derzeit etwa 1,5\% der Menschen in der (gesunden) Allgemeinbevölkerung nasal durch MRSA besiedelt [5]. Bei Patienten, die bei Krankenhausaufnahme untersucht werden, liegt diese Prävalenz regional und lokal unterschiedlich bei 1,5-2,5\% [6, 7]; in Punktprävalenzuntersuchungen im Gesundheitswesen bei 1,5 bis $>9 \%$ [8-10].

Die intestinale Kolonisation mit ESBL-E betrifft in Deutschland 3,5-6,8\% der Menschen in der Allgemeinbevölkerung; diese Prävalenz ist höher bei Patienten in Einrichtungen des Gesundheitswesens (- Tab. 1; Referenzen [9-17]). 36 bis $48 \%$ der ESBL-E. coli-Isolate aus der Allgemeinbevölkerung sowie $80 \%$ der ESBL-
E-Isolate aus Langzeitpflegeeinrichtungen waren zugleich Ciprofloxacin-resistent und erfüllten somit die Multiresistenzdefinition „3MRGN“ gemäß Kommission für Krankenhaushygiene und Infektionsprävention (KRINKO) [1, 10-12].

Passend zur Resistenzsituation in klinischen Untersuchungsmaterialien (https:// ars.rki) wurden in Sachsen 2012-2013 Kolonisationsraten für CRE von $<0,5 \%$ beschrieben [15]; auch in anderen Studien waren $<0,5 \%$ der ESBL-E-Isolate zusätzlich CRE [11, 12]. Auf Intensivstationen lag 2013-2014 die Prävalenz von CRE bei $<0,5 \%$ [18].

\section{Prävalenz bei Nutztieren und im Lebensmittel}

- Tab. 2 stellt Daten zum Vorkommen von MRSA und ESBL-E aus nutztierhaltenden Betrieben in Deutschland zusammen (Referenzen [19-24]). • Abb. 1 zeigt Kontaminationsraten von Fleischproben aus dem Einzelhandel (Referenzen: [25-30]). E. coli, die bei Fällen von Enteritis bei Kälbern isoliert wurden, waren 2011 in 26\% ESBL-E. Bei Untersuchung von Schwei-
nefleisch-Endprodukten am Schlachthof wurden 2008/2009 in 2/71 (3\%) MRSA nachgewiesen [31]. Hohe Kontaminationsraten von Geflügelfleisch (50-52\% bei Putenfleisch und 21-25\% bei Hähnchen) aus dem Einzelhandel wurden auch in anderen Untersuchungen in Deutschland nachgewiesen [32]. Untersuchungsergebnisse zur Kontamination von vegetabilen Lebensmitteln wurden in Deutschland wenig veröffentlicht; in anderen europäischen Ländern waren aber auch solche durch ESBL-E kontaminiert [30, 33]. ESBL-E und MRSA wurden auch in der Umgebung von Schweine- und Geflügelhaltungsanlagen in am Boden gewonnenen Proben außerhalb der Ställe sowie in geringen Keimzahlen auch in Luftsammelproben in $>100 \mathrm{~m}$ Entfernung zu den Ställen nachgewiesen [34-38].

\section{Prävalenz bei Begleittieren}

Die Prävalenz der (asymptomatischen) ESBL-E- und MRSA-Kolonisation bei Begleittieren (Hunden, Katzen, Pferden) ist unbekannt. Jedoch werden ESBL-E vermehrt im Rahmen klinischer Infektio- 
nen nachgewiesen [39-44]; auch das Vorkommen von Carbapenemase-bildenden E. coli und K. pneumoniae bei Hunden wurde gezeigt [45]. In einer deutschlandweiten Studie zum Vorkommen von $S$. aureus in zur Diagnostik eingesandten Wundabstrichen waren diese in $6 \%$ der Abstriche von Hunden, $12 \%$ von Katzen und $23 \%$ von Pferden nachweisbar. Dabei waren $63 \%$ der S. aureus-Isolate von Hunden, $47 \%$ von Katzen und $42 \%$ von Pferden als MRSA identifiziert worden [46]. In einer Untersuchung waren 6,3\% der Pferde enteral durch ESBLE besiedelt [47]. Zudem wurden ESBL-E bei wildlebenden Tieren (Ratten, Wasserund Raubvögel) nachgewiesen [48-50]. Daten der Germ-Vet- Studie weisen zwischen 2005/6 (0\%) und 2011 (4\%) einen Anstieg des Anteils von ESBL-E an allen E.coli-Isolaten von erkrankten Heimtieren auf $[51,52]$.

\section{Unterscheidbarkeit von MRSA- und ESBL-E-Isolaten von Tier und Mensch}

Die Mehrzahl (>90\%) der bei Nutztieren und im Lebensmittel nachgewiesenen MRSA ( = „livestock-associated“ [LA] MRSA) gehört der klonalen Linie „CC398“ an; seltener werden auch die Linien CC9, CC5 oder CC97 gefunden [53]. In Gesamtdeutschland machen MRSA CC398 und andere LA-MRSA etwa $2-5 \%$ der MRSA, die von Menschen isoliert werden, aus $[54,55]$. Die Mehrzahl der restlichen MRSA-Fälle entstehen durch „klassische“ Krankenhaus-assoziierte MRSA-Stämme; sog. „,community-associated“ (CA) MRSA sind selten (2-3\% aller MRSA) [55]. Jedoch ist zwischen 2004 und 2010 der Anteil von MRSA CC398 an allen MRSA-Nachweisen beim Menschen regional stark angestiegen [55]. In Gebieten mit hoher Nutztierhaltungsdichte (Nordrhein-Westfalen, Niedersachsen) repräsentieren MRSA CC398 heute bis zu $30 \%$ der in Krankenhäusern festgestellten nasalen MRSA-Besiedlungen und ca. $10 \%$ der MRSA-Infektionen von Menschen [56]. Die epidemiologische Bedeutung von MRSA, die das neue Methicillinresistenzgen $(\mathrm{mecC})$ aufweisen, ist noch unbekannt [57]. Der Ursprung von mecC-MRSA wird beim

Bundesgesundheitsbl 2016 ·59:113-123 DOI 10.1007/s00103-015-2261-z

(c) Springer-Verlag Berlin Heidelberg 2015

E.A. Idelevich · C. Lanckohr · D. Horn · L.H. Wieler · K. Becker · R. Köck

Antibiotika-resistente Erreger in Deutschland. Die Rolle
von nicht nosokomialen Ansteckungsquellen

\section{Zusammenfassung}

Hintergrund. Die Frage, ob die zunehmende Verbreitung von Erregern mit Antibiotika-Multiresistenzen (MRE) beim Menschen durch Übertragungen von Tieren erklärbar ist, wird öffentlich diskutiert.

Ziel der Arbeit. Diese Übersichtsarbeit trägt Daten zum Vorkommen von Methicillin-resistenten Staphylococcus aureus (MRSA) und Extended-Spectrum Beta-Lactamase (ESBL) bildenden Enterobakterien bei Mensch und Tier zusammen und beschreibt die Erkenntnisse zur zoonotischen Transmission.

Material und Methoden. Es wurde eine Literaturrecherche durchgeführt. Relevante Literatur wurde durch Screening von Überschriften und Abstracts identifiziert und ergänzt durch Publikationen von Infektions- schutzbehörden bzw. die dort zitierten Originalarbeiten.

Ergebnisse. Es zeigte sich eine Vielzahl nosokomialer Verbreitungswege von MRE sowie eine zunehmende Relevanz von außerhalb des Gesundheitswesens gelegenen Infektionsquellen.

Diskussion. Für eine effektive Prävention von MRE ist ein interdisziplinärer Ansatz notwendig, der sowohl die Grenzen medizinischer und pharmazeutischer Fachgebiete als auch die Grenzen zwischen Human- und Veterinärmedizin überschreitet.

Schlüsselwörter

Multiresistente Erreger - Deutschland .

Zoonose $\cdot$ Nutztier $\cdot$ Haustier

\section{Multidrug-resistant bacteria in Germany. The impact of sources outside healthcare facilities}

\section{Abstract}

Background. Currently, there is an ongoing discussion about the question whether the emergence of multidrug-resistant microorganisms (MDRO) among humans is due to transfer of these bacteria from animals.

Objectives. This review summarizes data on the occurrence of methicillin-resistant Staphylococcus aureus (MRSA) and extended-spectrum beta-lactamase (ESBL) producing enterobacteria in animals and humans, and describes knowledge about transmission pathways.

Material and methods. After a scientific literature analysis, relevant articles were identified by screening of titles and abstracts, amended by publications of infection control authorities and the respective reference lists. Results. MDRO are both transmitted in the nosocomial setting and are increasingly detected as sources of infection outside healthcare facilities.

Conclusions. Due to new transmission pathways of MDRO an inter-disciplinary approach towards prevention is necessary, involving medical, pharmaceutical and veterinary expertise.

\section{Keywords}

Antibiotics - Germany · Zoonosis - Livestock . Pets
Tier vermutet; ihr Anteil an allen MRSA scheint in Deutschland bei $<1 \%$ zu liegen [55, 58-60].

ESBL-E und CRE-Erreger werden wie MRSA ebenfalls „klonal“ übertragen. Zusätzlich tauschen verschiedene „Klone“ und Bakterienspezies jedoch auch mobile genetische Elemente (z. B. Plasmide) untereinander aus, die ESBL-Gene tragen. Deshalb ist es bei diesen Erregern zur Bewertung epidemiologischer $\mathrm{Zu}$ sammenhänge nicht ausreichend, klonale Unterschiede zu vergleichen [30, 61]. Die Durchführung einer Quellenzuordung für ESBL-E-Isolate ist zusätzlich limitiert durch fehlendes Grundlagenwissen zur Frage, ob verschiedene mobile genetische Elemente (z. B. Plasmide mit den Resistenzgenen blaCTX-M-1, blaCTX-M-15) und verschiedene Klone (z. B. ST131) mit denselben „Erfolgsraten“ in verschiedene Wirtsbakterien transferiert werden. - Abb. 2 zeigt einen Überblick über ESBL-E kodierende Gene, die bei Mensch und Nutztier in Europa in verschiedenen klonalen Linien von E. coli (u. a. ST131, ST648, ST38, ST393, ST10) gefunden wurden (Referenzen: [30, 61]). 


\section{Originalien und Übersichten}

Tab. 2 Prävalenz von MRSA und ESBL-E in Nutztierhaltungsbetrieben in Deutschland

\begin{tabular}{|lllll}
\hline Studie & Erreger & Betriebsart & $\begin{array}{l}\text { Anzahl } \\
\text { untersuchte } \\
\text { Betriebe }\end{array}$ & $\begin{array}{l}\text { Betriebs- } \\
\text { prävalenz }\end{array}$ \\
\hline Friese et al. [20] & MRSA & Pute & 5 & $40 \%$ \\
\hline Friese et al. [20] & MRSA & Hähnchen & 4 & $25 \%$ \\
\hline Friese et al. [20] & MRSA & Schweine (Mast) & 15 & $73 \%$ \\
\hline Köck et al. [24] & MRSA & Schweine & 40 & $70 \%$ \\
\hline Hering et al. [19] & $\begin{array}{l}\text { Cefotaxim-resistente } \\
\text { E. coli }\end{array}$ & Schweine (Mast) & 48 & $85 \%$ \\
\hline Friese et al. [20] & ESBL/AmpC-E. coli & Hähnchen & 8 & $100 \%$ \\
\hline Laube et al. [21] & ESBL/AmpC-E. coli & Hähnchen & 7 & $100 \%$ \\
\hline Friese et al. [20] & ESBL/AmpC-E. coli & Schweine (Zucht/Mast) & 16 & $44-56 \%$ \\
\hline Friese et al. [20] & ESBL/AmpC-E. coli & Milchvieh & 10 & $60 \%$ \\
\hline Schmid et al. [22] & ESBL-E. coli & Rinder und Milchvieh & 45 & $87 \%$ \\
\hline aAngabe in \% der Betriebe (nicht Tiere), auf denen der angegebene Erreger nachgewiesen wurde.
\end{tabular}

\section{Zoonotische Übertragungen}

Ein Risikofaktor für den Erwerb von MRSA-Besiedlungen außerhalb des Gesundheitswesens ist der direkte Kontakt zu landwirtschaftlichen Nutztieren; für ESBL-E wurde das Risiko der beruflichen Exposition bislang wenig untersucht (• Abb. 3; Referenzen [53, 62-65]). Typisierungsuntersuchungen beweisen, dass die erhöhte MRSA-Prävalenz bei diesen Personen auf eine dauerhaft nachweisbare Besiedlung mit MRSA CC398 zurückzuführen ist [66].

Unter Krankenhauspatienten im Münsterland wurden $38 \%$ der MRSACC398-Fälle jedoch bei Patienten ohne Nutztierkontakt nachgewiesen [67]. Mögliche Transmissionswege sind hier z. B. der private Kontakt zu Landwirten oder das Leben in Wohnhäusern auf landwirtschaftlichen Betrieben (ohne selbst dort $\mathrm{zu}$ arbeiten). Dies wird durch Studien aus den Niederlanden bestätigt und deutet darauf hin, dass es in landwirtschaftlich geprägten Regionen auch zu einer Tierkontakt-unabhängigen Verbreitung des Erregers kommt $[68,69]$. Eine Untersuchung in Niedersachsen zeigte aber, dass das Leben in der Nachbarschaft von Tierhaltungsanlagen kein Risikofaktor für MRSA-Besiedlung war [70]. Das Verbraucherrisiko für den Erwerb einer MRSABesiedlung durch Umgang mit kontaminierten Lebensmitteln wird in Deutschland derzeit als gering eingeschätzt [ 53 , 64, 71-73].
Dass ein Kontakt zu Begleittieren (Hunden, Katzen u. ä.) mit einem erhöhten Risiko für MRSA assoziiert sei, wurde nicht beschrieben. Umgekehrt wird aufgrund der genetischen Kongruenz von beim Haustier nachzuweisenden MRSAStämmen und „humanen“ Krankenhausassoziierten MRSA vermutet, dass Tierbesitzer ein Kolonisationsrisiko für ihr Haustier darstellen $[64,74,75]$. Bei Pferden dominierte in Mitteleuropa eine Sublinie vom LA-MRSA CC398 [74, 76]. Eine deutsche Studie zum Vergleich von humanen ESBL-E-Isolaten und solchen von Begleittieren deutete ebenfalls auf einen häufigen Austausch von Isolaten hin [77].

Risikofaktoren für einen zoonotischen ESBL-E-Erwerb wurden in verschiedenen Arbeiten beschrieben: In einzelnen Erhebungen aus Deutschland waren Risikofaktoren wie Kontakt zu Haustieren (Odds Ratio [OR] 6,7) und $\geq 3$-mal wöchentlicher Konsum von Schweinefleisch (OR 3,5) mit Besiedlung durch ESBL-E assoziiert $[13,78]$. Eine andere Erhebung fand keine signifikanten Unterschiede zwischen der Häufigkeit einer ESBL-E-Besiedlung bei Vegetariern und Menschen mit karnivoren Diätgewohnheiten (2,1 vs. $3,6 \% ; p=0,5)$ [79]. Der Konsum oder der Umgang mit rohem Geflügelfleisch wird von manchen Autoren jedoch als ein wichtiges Vehikel für ESBL-E-Kolonisation angesehen [30, 80, 81]. Andere Studien zeigen aber auf, dass aufgrund der durch Anwendung genetischer Fingerabdruckverfahren darstellbaren Unterschiedlichkeit von ESBL-E aus Fleisch und vom
Menschen Fleisch nur für einen (geringen?) Teil der humanen ESBL-E-Fälle verantwortlich sein kann [30, 61, 79]. Eine genaue Quantifizierung des Anteils der zoonotisch bedingten Fälle von ESBL-E ist auf der Basis dieser Daten und der oben dargestellten Limitationen bei der Interpretation von Typisierungsergebnissen nicht sicher möglich [30, 81, 82].

\section{Risikofaktor Reisen}

Einer der Hauptrisikofaktoren für eine Besiedlung durch ESBL-E sind Reisen. Bei einer ESBL-E-Kolonisationsrate von $6,8 \%$ vor Urlaubsreise, waren danach $30 \%$ der zuvor ESBL-negativen Urlauber $(n=191)$ durch ESBL-E. coli besiedelt; CRE wurden nicht nachgewiesen [14]. Die hohen ESBL-E-Besiedlungsraten bei Reiserückkehrern wurden auch in internationalen Studien gezeigt $[83,84]$. Die ESBL-E-Besiedlung war bei $9 \%$ der Urlauber sechs Monate nach Rückkehr persistent [14], was auch eine andere Untersuchung bestätigt [85]. Hinsichtlich der bereisten Urlaubsländer lag die ESBL-Besiedlungsrate bei Rückkehrern aus Indien $(73 \%)$ und Südostasien $(47,8 \%)$ am höchsten [14]. Zudem waren Reisen nach Griechenland und Afrika sowie ,asiatische Muttersprache" signifikant mit einer ESBL-E-Kolonisation assoziiert [13, 78]. Reisen sind auch ein Hauptrisikofaktor für den Erwerb von CA-MRSA-Stämmen, die in den USA sowie im südostasiatischen Raum verbreitet sind [7]. Ansteigende Anteile von CA-MRSA fanden sich bundesweit mit Schwerpunkt in den Metropolen Hamburg $(6,1 \%)$ und Frankfurt am Main (8,8\%) [55].

Auf die eingehende Darstellung der nosokomialen Risikofaktoren für MRSA und ESBL-E (z. B. wiederholter Krankenhausaufenthalt, Immobilität, vorangegangene Antibiotikatherapie) wird hier verzichtet; Daten hierzu wurden vielfach zusammenfassend dargestellt $[1,6,9,64,86]$.

\section{Diskussion}

Der zoonotische Anteil bei MRSA-Besiedlungen in Deutschland lässt sich schlaglichtartig wie folgt abschätzen, wobei größere regionale Unterschiede bestehen: Von 100.000 Menschen sind 1000- 


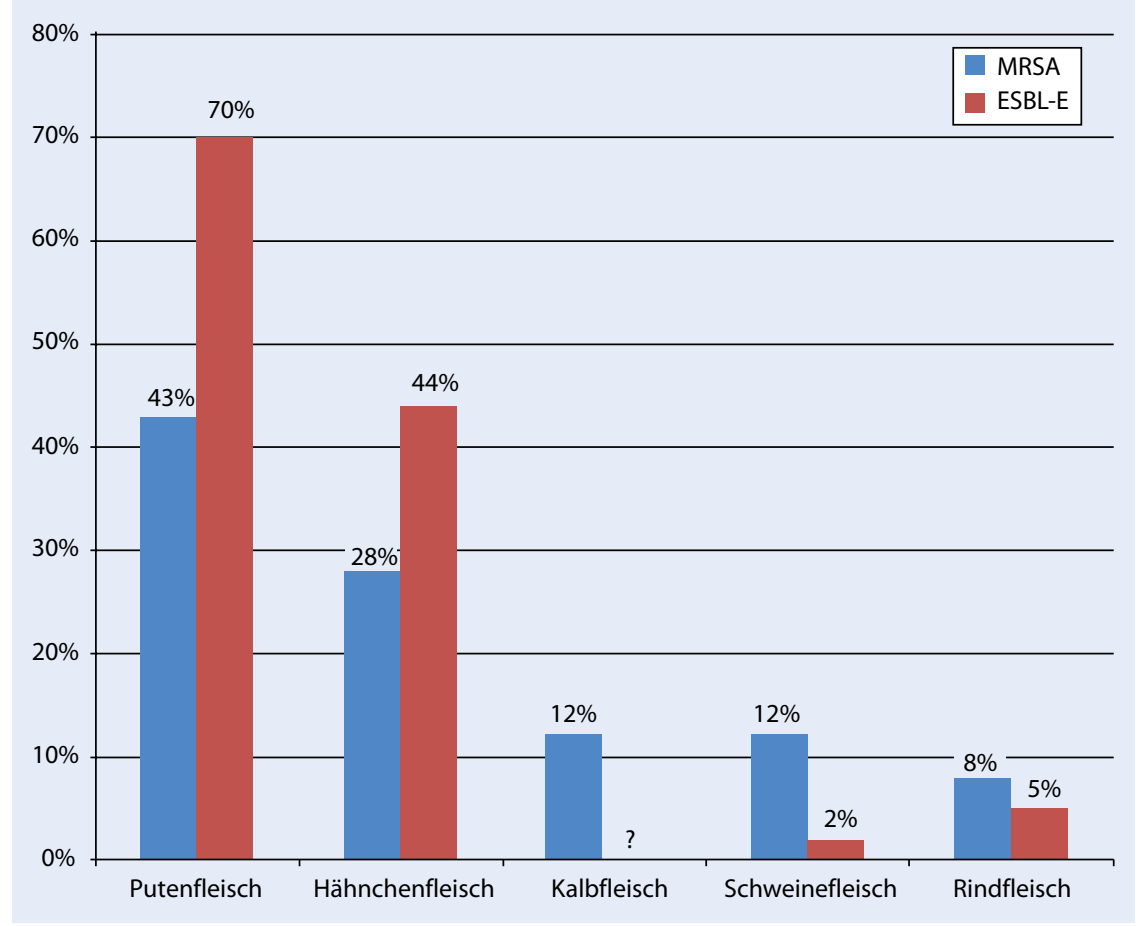

Abb. $1 \Delta$ Vorkommen von MRSA und ESBL-bildenden Enterobakterien in Fleisch aus dem Einzelhandel. „?" = keine Daten für Deutschland verfügbar; Referenzen siehe Text

1500 durch MRSA besiedelt; von diesen MRSA-Fällen macht die zoonotische klonale Linie CC398 in Gesamtdeutschland ca. $5 \%$ (d. h. ca. 50-75/100.000 Menschen), in durch landwirtschaftliche Nutztierhaltung geprägten Regionen wie dem Münsterland oder Niedersachsen ca. $30 \%$ (d. h. 300-500/100.000 Menschen) aus. Von allen MRSA-CC398-Kolonisierten haben etwa $62 \%$ den Erreger durch Nutztierkontakt erworben. Ein Präventionsziel bei Nutztierexponierten ist die Verhinderung der Kolonisation. Einzelne Studien haben gezeigt, dass sich MRSACC398-Besiedlungen bei Landwirten durch das Tragen von Staubschutzmasken im Stall günstig beeinflussen, jedoch nicht sicher vermeiden ließen $[87,88]$. Ein weiteres Präventionsziel ist die Verhinderung von endogenen MRSA-CC398-Infektionen nach medizinischen Interventionen, da der Erreger das Potenzial zur Generierung typischer, auch schwer verlaufender S. aureus-Infektionen besitzt [56, 89]. Deshalb empfiehlt die Kommission für Krankenhaushygiene und Infektionsprävention (KRINKO) ein präinterventionelles MRSA-Screening und nachfolgend eine Dekolonisierungstherapie bei Risikopatienten wie Landwirten und Tierärzten
Die Daten zu steigenden Nachweisraten von MRSA-Infektionen bei Haustieren (Hunden, Katzen) [46, 74], die auf einen wechselseitigen Austausch zwischen Mensch und Tier hindeuten, sollten Anlass geben, angesichts nachfolgender Zahlen basale Standards der Haushaltshygiene ins Gedächtnis zu rufen: Haustiere werden zunehmend als Familienmitglieder wahrgenommen [92]. $69 \%$ der Hundehalter erlauben es ihrem Tier, auf dem Sofa, $40 \%$, in ihren Betten zu liegen. Zudem erlauben $94 \%$ der Besitzer von Hunden dem Tier ihre Hände, $53 \%$, ihr Gesicht zu belecken [93].

Die zoonotische Komponente bei ESBL-E-Besiedlungen und -Infektionen des Menschen lässt sich aufgrund unzureichenden Grundlagenwissens nicht zuverlässig quantifizieren. Fest steht, dass es einen deutlichen Zuwachs von ESBL-E-Kolonisation in der Allgemeinbevölkerung und bei klinischen Isolaten gab.

Ein Hauptrisikofaktor für den Erwerb von ESBL-E sind Reisen nach Indien und Südostasien, wo sehr hohe Verbreitungsraten von ESBL-E in der Allgemeinbevölkerung (66\%), im Lebensmittel (>60\%), in Wasser und im Gesundheitswesen beschrieben wurden [94-105]. Insgesamt deutet sich in diesen Ländern an, dass das Zusammenspiel verschiedener Infektionsquellen für MRE (Tiere, Umwelt, Industrieabwässer, Krankenhäuser) zusammen mit hoher Bevölkerungsdichte sowie limitierter medizinischer Versorgung (auch freier Zugang zu Antibiotika) und sanitärer Ausstattung große Probleme darstellen [94-109]. Spezifische, über eine "gute Standardhygiene" hinausgehende Strategien zur Vermeidung solcher reiseassoziierten ESBL-E-Besiedlungen fehlen. Die Entwicklung solcher Strategien ist sicher vorrangig, insbesondere im Hinblick auf die künftige Eindämmung der Verbreitung von CRE. Auch wenn bisher zu CRE-Besiedlungsraten von Reiserückkehrern nur wenige Daten vorliegen, wurden in den vergangenen Jahren in Deutschland und in anderen Ländern immer wieder nosokomiale Ausbrüche durch CRE beschrieben, die durch einen Eintrag dieser Erreger aus dem Ausland (z. B. über Patienten, die aus dortigen Krankenhäusern übernommen wurden, Flüchtlinge) resultierten [110-113]. In Krankenhäu- 


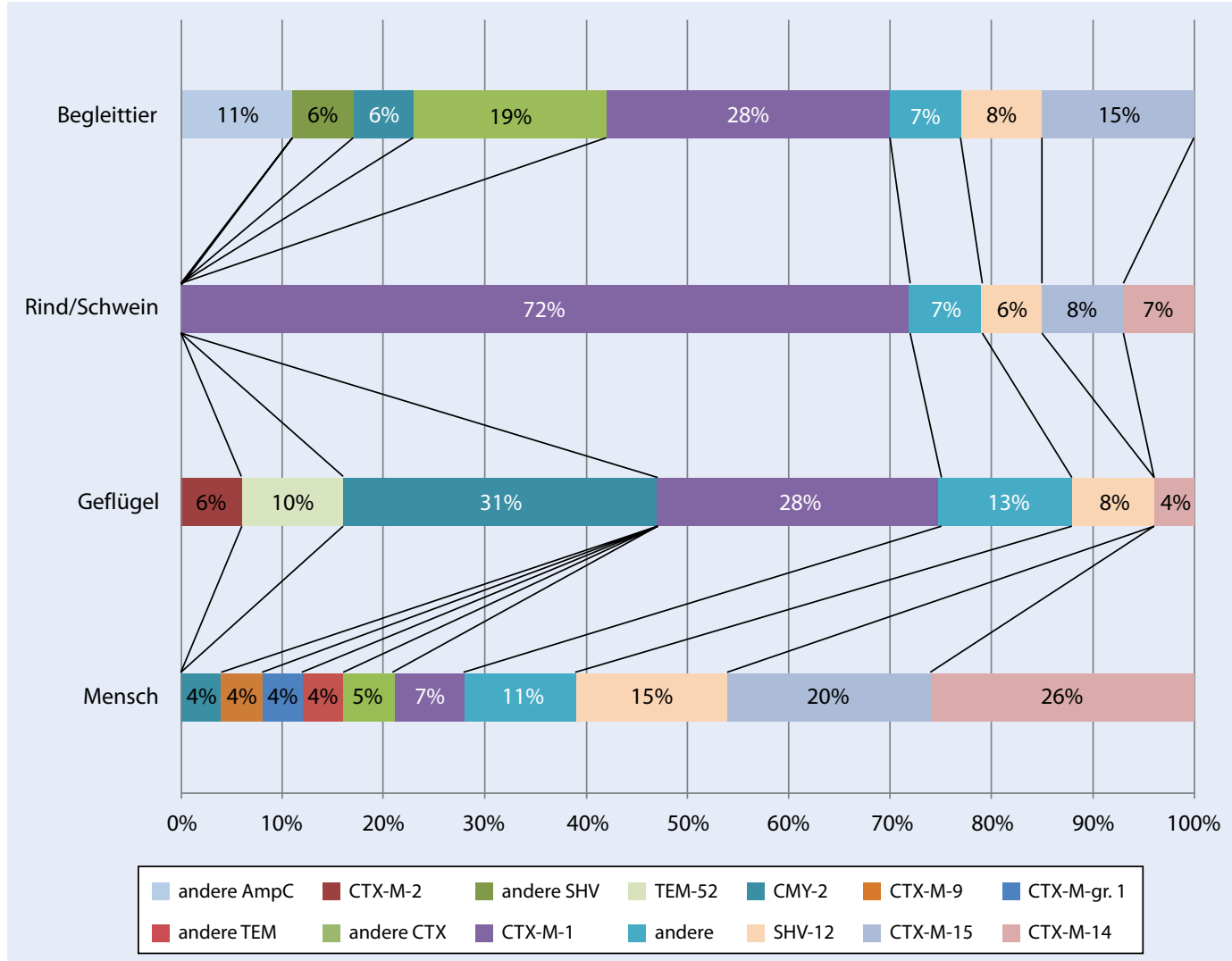

Abb. $2 \triangleleft$ Resistenzdeterminanten von ESBL-bildenden Enterobakterien bei Mensch und Tier. Abbildung nach Ewers $\mathrm{C}$. et al. [61] (Daten aus 100 verschiedenen Studien aus Europäischen Ländern). CTX, SHV, TEM, AmpC/CMY bezeichnen übertragbare Resistenzdeterminanten, die Unempfindlichkeit gegenüber Cephalosporinen der dritten Generation vermitteln können.

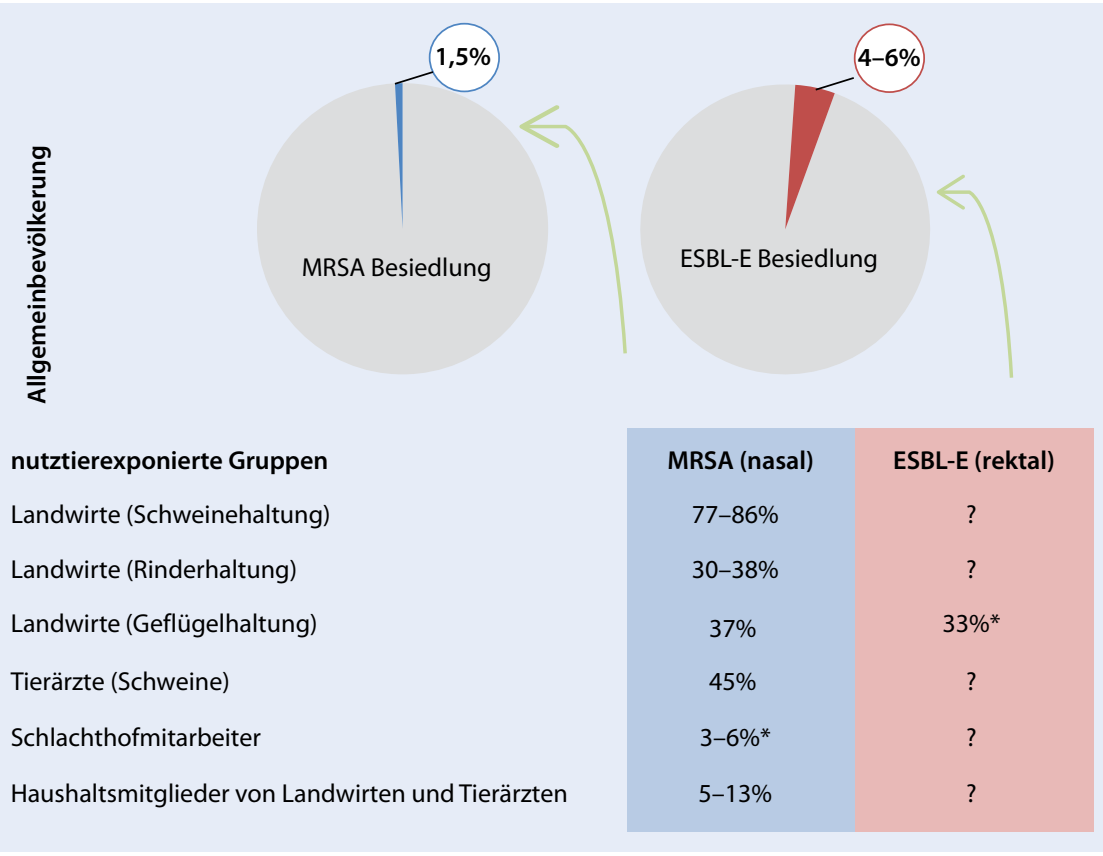

Abb. $3 \Delta$ Besiedlung durch MRSA und ESBL-bildende Enterobakterien bei nutztierexponierten Personen. ${ }^{*}$ Daten für Mitarbeiter in den Niederlanden, da für Deutschland keine Daten verfügbar sind; Referenzen siehe Text

sern wird bislang bei Reiserückkehrern und Nutztierexponierten kein Screening auf ESBL-E (bzw. „3MRGN“) empfohlen
[ 1 ]. Bei Letzteren fehlen Daten zur Kolonisationshäufigkeit, bei beiden fehlt der Nachweis einer effektiven infektions- oder transmissionspräventiven Wirksamkeit des Screenings. Hier herrscht dringender Bedarf an verlässlichen Daten.

Die Bedeutung von Abwässern sollte einer neuen Bewertung unterzogen werden, denn selektiv wirkende Antibiotikakonzentrationen konnten in städtischen Abwässern nachgewiesen werden [114]. Auch Oberflächengewässer könnten bei der Verbreitung von MRE eine wichtige Rolle spielen und z. B. zur Besiedlung von Wasservögeln, bei denen hohe Raten an ESBL-E gefunden wurden, beitragen [50].

Fraglich ist aber, ob Reisen den Anstieg von ESBL-E-Nachweisen in der Bevölkerung allein erklären können. Die aktuellen epidemiologischen Daten schließen nicht aus, dass ein Teil der ESBL-E-Besiedlungen durch den Umgang mit kontaminierten Lebensmitteln entsteht. Hierfür sprechen die parallel zum Vorkommen im Lebensmittel steigende Prävalenz in der Bevölkerung, die ähnliche Prävalenz bei nicht hospitalisierten Menschen in verschiedenen Regionen Deutschlands [12-14], aber auch die teilweise Kongruenz von Klonen und Resistenzdetermi- 
- Antiinfektivasurveillance \& freiwillige Benchmarkingsysteme

- Antibiotic Stewardship durch interdisziplinäre Teams von klinischen Infektiologen, Apothekern und Mikrobiologen und Hygienikern:

- lokale Leitlinien, Beratung, Fortbildung.

- proaktive Antiinfektiva-Verordnungsanalysen bzw. -Visiten

- Überprüfung von Qualitätsindikatoren zur Antiinfektivatherapie

- Re-Evaluation "alter" Antiinfektiva und Evaluation von Synergieeffekten durch Kombinationstherapien. Entwicklung neuer Antiinfektiva
- Rationaler Antiinfektivaeinsatz

- Antiinfektiva Leitlinien

- Entwicklung von Alternativen zu klassischen Antibiotika (z.B. Immuntherapie wie Einsatz monoklonaler Antikörper gegen Bestandteile der bakteriellen Zellen, spezifische Bakteriophagen-Endolysine, antimikrobiell wirksame Peptide, Pro- und Präbiotika, Bakterientherapie (z.B. Stuhltransplantation)

- Optimierte an minimale Hemmkonzentration (MHK) des Erregers angepasste

Dosierung von Antibiotika und therapeutisches Drug-Monitoring
- Evaluation neuer und sicherer Antibiotika-Applikationssysteme (Metaphylaktische Herdentherapie durch Gabe via Wasser oder Futter vs. Einzeltierbehandlung per Injektion)

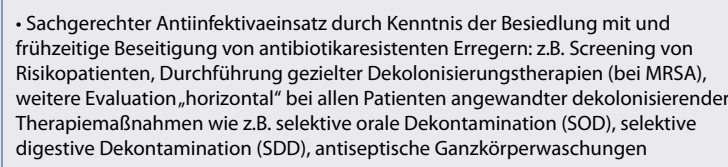

• Entwicklung alternativer Therapien sowie von Impfstoffen

Entwicklung von antiinfektiven Wirkstoffen, die nur in der Tierhaltung eingesetzt werden (?)
- Sachgerechter Antiinfektivaeinsatz durch

1.) Verbesserung der Tiergesundheit insbesondere bei infektionsgefährdeten Risikogruppen“ im Tierstall mit derzeit häufiger "metaphylaktisch" eingesetzter Antibiotika-Herdentherapie

2.) Verbesserung der Tierhaltungsbedingungen bei Nutztieren (z.B. Schaffung von Kompartimenten zur Separation kranker Tiere, Verbesserung der Fütterung, Optimierung von Hygienekonzepten)

Abb. 4 \ Strategien zur Förderung des sachgerechten Einsatzes von Antiinfektiva in der Human-und Veterinärmedizin

nanten beim Vergleich von ESBL-E-Isolaten aus dem Lebensmittel und vom Menschen (• Abb. 2). Die Vermeidung von Kreuzkontaminationen in der Küche kann deshalb ein Baustein der Prävention von ESBL-E sein $[115,116]$.

Die epidemiologischen Daten deuten darauf hin, dass ESBL-E-bezogene Präventionsansätze auch auf das Gesundheitswesen abzielen müssen. Dies lässt sich aus den in Krankenhäusern und Pflegeeinrichtungen deutlich höheren ESBL-E(Punkt-)-Prävalenzraten ableiten, die zum einen auf Übertragungen hinweisen und zum anderen durch vermehrte antibiotikabedingte Selektion bedingt sein könnten. Die formulierten Ideen und Ansätze zur Vorbeugung von Antiinfektivaresistenzen im Gesundheitswesen (• Abb. 4) sind deshalb entscheidend (Referenzen [1, 64, 117-142]). Neben den Bemühungen der Krankenhäuser, den rationalen Einsatz von Antiinfektiva zu fördern, sollte der Antibiotika-Selektionsdruck aber auch durch Maßnahmen im ambulanten Versorgungsbereich gering gehalten werden. Trotz im europäischen Vergleich recht niedriger Gesamtverschreibungsraten für Antibiotika sollte hier der in den vergangenen Jahren angestiegene Einsatz von Cephalosporinen der zweiten Generation (Cefuroximaxetil) und Fluorchinolonen (Ciprofloxacin) hinterfragt werden [51].

In Krankenhäusern wird bislang bei Reiserückkehrern und Nutztierexponierten kein Screening auf ESBL-E (bzw. „3MRGN“) empfohlen [1]. Bei Letzteren fehlen Daten zur Kolonisationshäufigkeit, bei beiden fehlt der Nachweis einer effektiven infektions- oder transmissionspräventiven Wirksamkeit des Screenings. Hier herrscht dringender Bedarf an verlässlichen Daten.

\section{Fazit}

Insgesamt zeigt sich, dass neue zoonotische Infektionsquellen Einfluss auf das Vorkommen von ESBL-E und MRSA beim Menschen haben. Jedoch ist der Einfluss dieser Infektionsquellen teils regional unterschiedlich (MRSA), teils schwer quantifizierbar (ESBL-E). Sowohl die Human- als auch die Veterinärmedizin müssen künftig durch rationale(re)n Antibiotikaeinsatz (auch unter Berücksichtigung innovativer pharmazeutischer Konzepte sowie soziologischer Forschung), Barriere- und Dekolonisierungsmaßnahmen und andere Infektionskontrollstrategien versuchen, im Sinne eines „OneHealth"-Gedankens die Verbreitung von MRE einzudämmen. Dies schließt die Betrachtung der Umwelt ein, insbesondere muss die Bedeutung von Abwässern 
und Oberflächengewässern intensiver untersucht werden. Interdisziplinäre Antibiotic-Stewardship-Teams, die im humanmedizinischen Bereich die Ziele der Deutschen Antibiotika-Resistenzstrategie (DART) umsetzen, müssen beachten, dass Quellen für MRE zunehmend auch außerhalb des Krankenhauses zu finden sind, und sollten dies bei ihren (lokalen und regionalen) Empfehlungen zur rationalen Antibiotikagabe insbesondere bei der kalkulierten Therapie von Infektionen berücksichtigen.

\section{Korrespondenzadresse}

\section{Priv.-Doz. Dr. med R. Köck}

Institut für Medizinische Mikrobiologie, Universitätsklinikum Münster, 48149 Münster robin.koeck@ukmuenster.de

\section{Einhaltung ethischer Richtlinien}

Interessenkonflikte. Prof. Dr. Wieler, Prof. Dr. Becker und Priv.-Doz. Dr. Köck erhielten/erhalten Förderungen im Rahmen der Zoonose-Forschungsverbünde „FBI-Zoo" bzw. „,MedVet-Staph" durch das Bundesministerium für Bildung und Forschung. Dr. Idelevich erhielt Förderungen im Rahmen des Programms "Innovative Medizinische Forschung" (IMF) der Medizinischen Fakultät der Universität Münster für die Untersuchungen zur Prävention und Therapie mit Bakteriophagenendolysinen.

Priv.-Doz. Dr. Köck erhielt Zuwendungen von Becton Dickinson, Pfizer, Paul Hartmann, B. Braun Melsungen, MSD Sharpe \& Dohme und Astellas Pharma. Prof. Dr. Becker erhielt Zuwendungen von Cepheid, Cubist, Novartis, Oxoid, Pfizer und Siemens. Dr. Lanckohr erhielt Zuwendungen von Astellas Pharma, Pfizer, Novartis und Sanofi. Dr. Idelevich erhielt Zuwendungen von Pfizer, Astellas Pharma und Novartis.

Dieser Beitrag enthält keine Studien an Menschen oder Tieren.

\section{Literatur}

1. Kommission für Krankenhaushygiene und Infektionsprävention (KRINKO) (2012) Hygienemaßnahmen bei Infektionen oder Besiedlung mit multiresistenten gramnegativen Stäbchen. Bundesgesundheitsbl Gesundheitsforsch Gesundheitsschutz 55:1311-1354

2. Kaase M (2014) Bericht des Nationalen Referenzzentrums für gramnegative Krankenhauserreger (1. Januar 2013 bis 31. Dezember 2013). EpiBull 43:421-425

3. Wellington EM, Boxall AB, Cross P et al (2013) The role of the natural environment in the emergence of antibiotic resistance in gram-negative bacteria. Lancet Infect Dis 13:155-165

4. Rodriguez-Rojas A, Rodriguez-Beltran J, Couce A, Blazquez J (2013) Antibiotics and antibiotic resistance: a bitter fight against evolution. Int J Med Microbiol 303:293-297
5. Mehraj J, Akmatov MK, Strompl J et al (2014) Methicillin-sensitive and methicillin-resistant Staphylococcus aureus nasal carriage in a random sample of non-hospitalized adult population in northern Germany. PLoS One 9:e107937

6. Herrmann M, Petit C, Dawson A et al (2013) Methicillin-resistant Staphylococcus aureus in Saarland, Germany: a statewide admission prevalence screening study. PLoS One 8:e73876

7. Köck R, Mellmann A, Schaumburg F, Friedrich AW, Kipp F, Becker K (2011) The epidemiology of methicillin-resistant Staphylococcus aureus (MRSA) in Germany. Dtsch Arztebl Int 108:761767

8. Wegner C, Hübner NO, Gleich S, Thalmaier U, Krüger CM, Kramer A (2013) One-day point prevalence of emerging bacterial pathogens in a nationwide sample of 62 German hospitals in 2012 and comparison with the results of the one-day point prevalence of 2010. GMS Hyg Infect Control 8(1):Doc12

9. Gruber I, Heudorf U, Werner G et al (2013) Multidrug-resistant bacteria in geriatric clinics, nursing homes, and ambulant care-prevalence and risk factors. Int J Med Microbiol 303:405-409

10. Heudorf U, Gustav C, Mischler D, Schulze J (2014) Healthcare associated infections (HAI), antibiotic use and prevalence of multidrug-resistant bacteria (MDRO) in residents of long-term care facilities: the Frankfurt HALT plus MDRO project 2012 Bundesgesundheitsbl Gesundheitsforsch Gesundheitsschutz 57:414-422

11. Valenza G, Nickel S, Pfeifer Y et al (2014) Extended-spectrum-beta-lactamase-producing Escherichia coli as intestinal colonizers in the German community. Antimicrob Agents Chemother 58:1228-1230

12. Belmar Campos C, Fenner I, Wiese N et al (2014) Prevalence and genotypes of extended spectrum beta-lactamases in Enterobacteriaceae isolated from human stool and chicken meat in Hamburg, Germany. Int J Med Microbiol 304:678-684

13. Meyer E, Gastmeier P, Kola A, Schwab F (2012) Pet animals and foreign travel are risk factors for colonisation with extended-spectrum beta-lactamase-producing Escherichia coli. Infection 40:685-687

14. Lübbert C, Straube L, Stein C et al (2015) Colonization with extended-spectrum beta-lactamaseproducing and carbapenemase-producing Enterobacteriaceae in international travelers returning to Germany. Int J Med Microbiol 305:148156

15. Ehrhard I, Karaalp AK, Hackel T et al (2014) Prevalence of carbapenemase-producing bacteria in hospitals in Saxony, Germany. Bundesgesundheitsbl Gesundheitsforsch Gesundheitsschutz 57:406-413

16. Vehreschild MJ, Hamprecht A, Peterson L et al (2014) A multicentre cohort study on colonization and infection with ESBL-producing Enterobacteriaceae in high-risk patients with haematological malignancies. J Antimicrob Chemother 69:3387-3392

17. Arvand M, Moser V, Pfeifer Y (2013) Prevalence of extended-spectrum-beta-lactamase-producing Escherichia coli and spread of the epidemic clonal lineage ST131 in nursing homes in Hesse, Germany. J Antimicrob Chemother 68:26862688
18. Maechler F, Pena Diaz LA, Schröder C, Geffers C, Behnke M, Gastmeier P (2015) Prevalence of carbapenem-resistant organisms and other Gramnegative MDRO in German ICUs: first results from the national nosocomial infection surveillance system (KISS). Infection 43:163-168

19. Hering J, Hille K, Fromke C et al (2014) Prevalence and potential risk factors for the occurrence of cefotaxime resistant Escherichia coli in German fattening pig farms - A cross-sectional study. Prev Vet Med 116:129-137

20. Friese A, Schulz J, Laube H, von Salviati C, Hartung J, Roesler U (2013) Faecal occurrence and emissions of livestock-associated methicillin-resistant Staphylococcus aureus (laMRSA) and ESbl/AmpC-producing E. coli from animal farms in Germany. Berl Munch Tierarztl Wochenschr 126:175-180

21. Laube $H$, Friese $A$, von Salviati $C$ et al (2013) Longitudinal monitoring of extended-spectrum-beta-lactamase/AmpC-producing Escherichia coIi at German broiler chicken fattening farms. Appl Environ Microbiol 79:4815-4820

22. Schmid A, Hormansdorfer $S$, Messelhausser U, Käsbohrer A, Sauter-Louis C, Mansfeld R (2013) Prevalence of extended-spectrum beta-lactamase-producing Escherichia coli on bavarian dairy and beef cattle farms. Appl Environ Microbiol 79:3027-3032

23. Hille K, Fischer J, Falgenhauer L et al (2014) On the occurence of Extended-spectrum- and AmpC-betalactamase- producing Escherichia coli in livestock: results of selected European studies. Berl Munch Tierarztl Wochenschr 127:403-411

24. Köck R, Harlizius J, Bressan N et al (2009) Prevalence and molecular characteristics of methicillin-resistant Staphylococcus aureus (MRSA) among pigs on German farms and import of livestock-related MRSA into hospitals. Eur J Clin Microbiol Infect Dis 28:1375-1382

25. Bundesamt für Verbraucherschutz und Lebensmittelsicherheit (BVL) (2010) Berichte zur Lebensmittelsicherheit 2009: Zoonosen-Monitoring. Springer, Basel

26. Bundesamt für Verbraucherschutz und Lebensmittelsicherheit (BVL) (2012) Berichte zur Lebensmittelsicherheit 2010: Zoonosen-Monitoring. Springer, Basel

27. Bundesamt für Verbraucherschutz und Lebensmittelsicherheit (BVL) (2013) Berichte zur Lebensmittelsicherheit 2011: Zoonosen-Monitoring. Springer, Basel

28. Bundesamt für Verbraucherschutz und Lebens mittelsicherheit (BVL) (2014) Berichte zur Lebensmittelsicherheit 2012: Zoonosen-Monitoring. Springer, Basel

29. Kola A, Kohler C, Pfeifer Y et al (2012) High prevalence of extended-spectrum-beta-lactamase-producing Enterobacteriaceae in organic and conventional retail chicken meat, Germany. J Antimicrob Chemother 67:2631-2634

30. Sharp H, Valentin L, Fischer J, Guerra B, Appel B, Käsbohrer A (2014) Estimation of the transfer of ESBL-producing Escherichia coli to humans in Germany. Berl Munch Tierarztl Wochenschr 127:464-477

31. Beneke B, Klees S, Stuhrenberg B, Fetsch A, Kraushaar B, Tenhagen BA (2011) Prevalence of methicillin-resistant Staphylococcus aureus in a fresh meat pork production chain. J Food Prot 74:126-129 
32. Feßler AT, Kadlec K, Hassel M et al (2011) Characterization of methicillin-resistant Staphylococcus aureus isolates from food and food products of poultry origin in Germany. Appl Environ Microbiol 77:7151-7157

33. Reuland EA, AI Naiemi N, Raadsen SA, Savelkoul PH, Kluytmans JA, Vandenbroucke-Grauls CM (2014) Prevalence of ESBL-producing Enterobacteriaceae in raw vegetables. Eur J Clin Microbiol Infect Dis 33:1843-1846

34. von Salviati C, Laube H, Guerra B, Roesler U, Friese $A$ (2015) Emission of ESBL/AmpC-producing Escherichia coli from pig fattening farms to surrounding areas. Vet Microbiol 175:77-84

35. Schulz J, Friese A, Klees S et al (2012) LA-MRSA contamination of air and soil surfaces in the vicinity of pig barns: a longitudinal study. Appl Environ Microbiol 78:5666-5671

36. Friese A, Schulz J, Hoehle L et al (2012) Occurrence of MRSA in air and housing environment of pig barns. Vet Microbiol 158:129-135

37. Laube H, Friese A, von Salviati C, Guerra B, Rösler U (2014) Transmission of ESBL/AmpC-producing Escherichia coli from broiler chicken farms to surrounding areas. Vet Microbiol 172:519-527

38. Friese A, Schulz J, Zimmermann K et al (2013) Oc currence of livestock-associated methicillin-resistant Staphylococcus aureus in turkey and broiler barns and contamination of air and soil surfaces in their vicinity. Appl Environ Microbiol 79:27592766

39. Ewers C, Bethe A, Stamm I et al (2014) CTX-M-15 D-ST648 Escherichia coli from companion animals and horses: another pandemic clone combining multiresistance and extraintestinal virulence? J Antimicrob Chemother 69:1224-1230

40. Ewers C, Grobbel M, Bethe A, Wieler LH, Guenther $S$ (2011) Extended-spectrum beta-lactamases-producing gram-negative bacteria in companion animals: action is clearly warranted! Berl Munch Tierarzt। Wochenschr 124:94-101

41. Weese JS (2007) MRSA infection in horses. Vet Rec 161:359-360

42. Seguin JC, Walker RD, Caron JP et al (1999) Methicillin-resistant Staphylococcus aureus outbreak in a veterinary teaching hospital: potential human-to-animal transmission. J Clin Microbiol 37:1459-1463

43. Dargatz DA, Traub-Dargatz JL (2004) Multidrugresistant Salmonella and nosocomial infections. Vet Clin North Am Equine Pract 20:587-600

44. Boerlin P, Eugster S, Gaschen F, Straub R, Schawalder P (2001) Transmission of opportunistic pathogens in a veterinary teaching hospital. Vet Microbiol 82:347-359

45. Stolle I, Prenger-Berninghoff E, Stamm I et al (2013) Emergence of OXA-48 carbapenemase-producing Escherichia coli and Klebsiella pneumoniae in dogs. J Antimicrob Chemother 68:2802-2808

46. Vincze S, Stamm I, Kopp PA et al (2014) Alarming proportions of methicillin-resistant Staphylococcus aureus (MRSA) in wound samples from companion animals, Germany 2010-2012. PLoS One 9:e85656

47. Maddox TW, Clegg PD, Diggle PJ et al (2012) Cross-sectional study of antimicrobial-resistant bacteria in horses. Part 1: prevalence of antimicrobial-resistant Escherichia coli and methicillin-resistant Staphylococcus aureus. Equine Vet J 44:289-296
48. Guenther S, Aschenbrenner K, Stamm I et al (2012) Comparable high rates of extended-spectrum-beta-lactamase-producing Escherichia coli in birds of prey from Germany and Mongolia. PLoS One 7:e53039

49. Guenther S, Bethe A, Fruth A et al (2012) Frequent combination of antimicrobial multiresistance and extraintestinal pathogenicity in Escherichia coli isolates from urban rats (Rattus norvegicus) in Berlin, Germany. PLoS One 7:e50331

50. Guenther S, Ewers C, Wieler LH (2011) Extendedspectrum beta-lactamases producing $E$. coli in wildlife, yet another form of environmental pollution? Front Microbiol 2:246

51. GERMAP 2012: Antibiotika-Resistenz und -Verbrauch - Bericht über den Antibiotikaverbrauch und die Verbreitung von Antibiotikaresistenzen in der Human- und Veterinärmedizin in Deutschland. 2014. http://www.bvl.bund.de/SharedDocs/Downloads/05_Tierarzneimittel/germap2012.pdf?_blob=publicationFile \&v $=4 . \mathrm{Zu}$ gegriffen: 1. Feb. 2015

52. Schink AK, Kadlec K, Kaspar H, Mankertz J, Schwarz S (2013) Analysis of extended-spectrum-beta-lactamase-producing Escherichia coli isolates collected in the GERM-Vet monitoring programme. J Antimicrob Chemother 68:17411749

53. Köck R, Ballhausen B, Bischoff M et al (2014) The burden of zoonotic MRSA colonization and infection in Germany. Berl Munch Tierarztl Wochenschr 127:384-398

54. Layer F, Cuny C, Strommenger B, Werner G, Witte W (2012) [Current data and trends on methicillinresistant Staphylococcus aureus (MRSA)]. Bundesgesundheitsbl Gesundheitsforsch Gesundheitsschutz 55:1377-1386

55. Schaumburg F, Köck R, Mellmann A et al (2012) Population dynamics among methicillin resistant Staphylococcus aureus in Germany during a 6-year period. J Clin Microbiol 50:3186-3192

56. Köck R, Schaumburg F, Mellmann A et al (2013) Livestock-associated methicillin-resistant Staphylococcus aureus (MRSA) as causes of human infection and colonization in Germany. PLoS One 8:e55040

57. Becker K, Ballhausen B, Köck R, Kriegeskorte A (2014) Methicillin resistance in Staphylococcus isolates: the "mec alphabet" with specific consideration of $m e c C$, a mec homolog associated with zoonotic S. aureus lineages. Int J Med Microbiol 304:794-804

58. Kriegeskorte A, Ballhausen B, Idelevich EA et al (2012) Human MRSA isolates with novel genetic homolog, Germany. Emerg Infect Dis 18:10161018

59. Cuny C, Layer F, Strommenger B, Witte W (2011) Rare occurrence of methicillin-resistant Staphylococcus aureus $\mathrm{CC} 130$ with a novel me$C A$ homologue in humans in Germany. PLoS One 6:e24360

60. Walther B, Wieler LH, Vincze S et al (2012) MRSA variant in companion animals. Emerg Infect Dis 18:2017-2020

61. Ewers C, Bethe A, Semmler T, Guenther S, Wieler LH (2012) Extended-spectrum beta-lactamaseproducing and AmpC-producing Escherichia coli from livestock and companion animals, and their putative impact on public health: a global perspective. Clin Microbiol Infect 18:646-655

62. Richter A, Sting R, Popp C et al (2012) Prevalence of types of methicillin-resistant Staphylococcus aureus in turkey flocks and personnel attending the animals. Epidemiol Infect 140 2223-2232
63. Dahms C, Hübner NO, Cuny C, Kramer A (2014) Occurrence of methicillin-resistant Staphylococcus aureus in farm workers and the livestock environment in Mecklenburg-Western Pomerania, Germany. Acta Vet Scand 56:53

64. Kommission für Krankenhaushygiene und Infektionsprävention (KRINKO) (2014) Empfehlungen zur Prävention und Kontrolle von Methicillinresistenten Staphylococcus-aureus-Stämmen (MRSA) in medizinischen und pflegerischen Einrichtungen. Bundesgesundheitsbl Gesundheitsforsch Gesundheitsschutz 57:696-732

65. Dierikx C, van der Goot J, Fabri T, van Essen-Zandbergen A, Smith H, Mevius D (2013) Extendedspectrum-beta-lactamase- and AmpC-beta-lactamase-producing Escherichia coli in Dutch broilers and broiler farmers. J Antimicrob Chemother 68:60-67

66. Köck R, Loth B, Koksal M, Schulte-Wulwer J, Harlizius J, Friedrich AW (2012) Persistence of nasal colonization with livestock-associated methicillin-resistant Staphylococcus aureus in pig farmers after holidays from pig exposure. Appl Environ Microbiol 78:4046-4047

67. Deiters C, Günnewig V, Friedrich AW, Mellmann A, Köck R (2015) Are cases of Methicillin-resistant Staphylococcus aureus clonal complex (CC) 398 among humans still livestock-associated? Int J Med Microbiol 305:110-113

68. Feingold BJ, Silbergeld EK, Curriero FC, van Cleef BA, Heck ME, Kluytmans JA (2012) Livestock density as risk factor for livestock-associated methicillin-resistant Staphylococcus aureus, the Netherlands. Emerg Infect Dis 18:1841-1849

69. van Rijen MM, Bosch T, Verkade EJ, Schouls L, Kluytmans JA, Group CAMS (2014) Livestock-associated MRSA carriage in patients without direct contact with livestock. PLoS One 9:e100294

70. Bisdorff B, Scholholter JL, Claussen K, Pulz M, Nowak D, Radon K (2012) MRSA-ST398 in livestock farmers and neighbouring residents in a rural area in Germany. Epidemiol Infect 140:18001808

71. Dahms C, Hübner NO, Wilke F, Kramer A (2014) Mini-review: Epidemiology and zoonotic potential of multiresistant bacteria and Clostridium difficile in livestock and food. GMS Hyg Infect Control 9:Doc21

72. Wendlandt S, Schwarz S, Silley P (2013) Methicillin-resistant Staphylococcus aureus: a food-borne pathogen? Annu Rev Food Sci Technol 4:117139

73. Bundesinstitut für Risikobewertung (2009) Menschen können sich über den Kontakt mit Nutztieren mit Methicillin-resistenten Staphylococcus aureus (MRSA) infizieren. Stellungnahme Nr. 014/2009. http://www.bfr.bund.de/cm/208/ menschen_koennen_sich_ueber_den_kontakt_ mit_nutztieren_mit_mrsa_infizieren.pdf. Zugegriffen: 9. Juni 2015

74. Vincze $S$, Brandenburg AG, Espelage W et al (2014) Risk factors for MRSA infection in companion animals: results from a case-control study within Germany. Int J Med Microbiol 304:787793

75. Nienhoff U, Kadlec K, Chaberny IF et al (2009) Transmission of methicillin-resistant Staphylococcus aureus strains between humans and dogs: two case reports. J Antimicrob Chemother 64:660-662 
76. Abdelbary MM, Wittenberg A, Cuny C et al (2014) Phylogenetic analysis of Staphylococcus aureus CC398 reveals a sub-lineage epidemiologically associated with infections in horses. PLoS One 9:e88083

77. Schmiedel J, Falgenhauer L, Domann E et al (2014) Multiresistant extended-spectrum betalactamase-producing Enterobacteriaceae from humans, companion animals and horses in central Hesse, Germany. BMC Microbiol 14:187

78. Leistner R, Meyer E, Gastmeier P et al (2013) Risk factors associated with the community-acquired colonization of extended-spectrum beta-lactamase (ESBL) positive Escherichia Coli. An exploratory case-control study. PLoS One 8:e74323

79. Königer D, Gastmeier P, Kola A, Schwab F, Meyer $E$ (2014) Vegetarians are not less colonized with extended-spectrum-beta-lactamase-producing bacteria than meat eaters. J Antimicrob Chemother 69:281-282

80. Kluytmans JA, Overdevest IT, Willemsen I et al (2013) Extended-spectrum beta-lactamase-producing Escherichia coli from retail chicken meat and humans: comparison of strains, plasmids, resistance genes, and virulence factors. Clin Infect Dis 56:478-487

81. Valentin L, Sharp H, Hille K et al (2014) Subgrouping of ESBL-producing Escherichia coli from animal and human sources: an approach to quantify the distribution of ESBL types between different reservoirs. Int J Med Microbiol 304:805816

82. Bundesinstitut für Risikobewertung (2011) ESBLbildende Bakterien in Lebensmitteln und deren Übertragbarkeit auf den Menschen. Stellungnahme Nr. 002/2012 des BfR vom 5. Dezember 2011. http://www.bfr.bund.de/cm/343/esbl-bildendebakterien-in-lebensmitteln-und-deren-uebertragbarkeit-auf-den-menschen.pdf. Zugegriffen: 12. Jan. 2015

83. von Wintersdorff CJ, Penders J, Stobberingh EE et al (2014) High rates of antimicrobial drug resistance gene acquisition after international travel, The Netherlands. Emerg Infect Dis 20:649-657

84. Jorgensen SB, Samuelsen O, Sundsfjord A et al (2014) High prevalence of faecal carriage of ESBL-producing Enterobacteriaceae in Norwegian patients with gastroenteritis. Scand J Infect Dis 46:462-465

85. Tham J, Walder M, Melander E, Odenholt I (2012) Duration of colonization with extended-spec trum beta-lactamase-producing Escherichia coli in patients with travellers' diarrhoea. Scand J Infect Dis 44:573-577

86. Mutters NT, Mersch-Sundermann V, Mutters R, Brandt C, Schneider-Brachert W, Frank U (2013) Control of the spread of vancomycin-resistant Enterococci in hospitals: epidemiology and clinical relevance. Dtsch Arztebl Int 110:725-731

87. Verkade $E$, van Benthem B, den Bergh MK et al (2013) Dynamics and determinants of Staphylococcus aureus carriage in livestock veterinarians: a prospective cohort study. Clin Infect Dis 57:e11-e17

88. Nathaus R, Schulz J, Hartung J et al (2011) [Investigations into the use of respiratory masks for reducing the MRSA-exposure of veterinarians visiting regularly pig herds - first experiences]. Berl Munch Tierarztl Wochenschr 124:128-135
89. Ballhausen $B$, Jung $P$, Kriegeskorte $A$ et al (2014) LA-MRSA CC398 differ from classical community acquired-MRSA and hospital acquired-MRSA lineages: functional analysis of infection and colonization processes. Int J Med Microbiol 304:777786

90. Köck R, Becker K, Cookson B et al (2014) Systematic literature analysis and review of targeted preventive measures to limit healthcare-associated infections by meticillin-resistant Staphylococcus aureus. Euro Surveill 19:pii: 20860

91. Jurke A, Köck R, Becker K et al (2013) Reduction of the nosocomial meticillin-resistant Staphylococcus aureus incidence density by a regionwide search and follow-strategy in forty German hospitals of the EUREGIO, 2009 to 2011. Euro Surveill 18:pii $=20579$

92. Blouin DD (2008) All in the family? understanding the meaning of dogs and cats in the Lives of American pet owners. Indiana University, Bloomington

93. Walther B, Hermes J, Cuny C et al (2012) Sharing more than friendship - nasal colonization with coagulase-positive Staphylococci (CPS) and co-habitation aspects of dogs and their owners. PLoS One 7:e35197

94. Sasaki T, Hirai I, Niki M et al (2010) High prevalence of CTX-M beta-lactamase-producing Enterobacteriaceae in stool specimens obtained from healthy individuals in Thailand. J Antimicrob Chemother 65:666-668

95. Luvsansharav UO, Hirai I, Nakata A et al (2012) Prevalence of and risk factors associated with faecal carriage of CTX-M beta-lactamase-producing Enterobacteriaceae in rural Thai communities. J Antimicrob Chemother 67:1769-1774

96. Boonyasiri A, Tangkoskul T, Seenama C, Saiyarin J, Tiengrim S, Thamlikitkul V (2014) Prevalence of antibiotic resistant bacteria in healthy adults, foods, food animals, and the environment in selected areas in Thailand. Pathog Glob Health 108:235-245

97. Hsueh PR, Hoban DJ, Carmeli Y et al (2011) Consensus review of the epidemiology and appropriate antimicrobial therapy of complicated urinary tract infections in Asia-Pacific region. J Infect 63:114-123

98. Bajpai T, Shrivastava G, Bhatambare GS, Deshmukh AB, Chitnis V (2013) Microbiological profile of lower respiratory tract infections in neurological intensive care unit of a tertiary care center from Central India. J Basic Clin Pharm 4:51-55

99. Kumarasamy KK, Toleman MA, Walsh TR et al (2010) Emergence of a new antibiotic resistance mechanism in India, Pakistan, and the UK: a molecular, biological, and epidemiological study. Lancet Infect Dis 10:597-602

100. Boxall AB, Rudd MA, Brooks BW et al (2012) Pharmaceuticals and personal care products in the environment: what are the big questions? Environ Health Perspect 120:1221-1229

101. Larsson DG (2014) Antibiotics in the environment. Ups J Med Sci 119:108-112

102. Johnning A, Moore ER, Svensson-Stadler $L$, Shouche YS, Larsson DG, Kristiansson E (2013) Acquired genetic mechanisms of a multiresistant bacterium isolated from a treatment plant receiving wastewater from antibiotic production. Appl Environ Microbiol 79:7256-7263

103. Rutgersson C, Fick J, Marathe $\mathrm{N}$ et al (2014) Fluoroquinolones and qnr genes in sediment, water, soil, and human fecal flora in an environment polluted by manufacturing discharges. Environ Sci Technol 48:7825-7832
104. Ahmad A, Patel I, Mohanta G, Balkrishnan R (2014) Evaluation of self medication practices in rural area of town Sahaswan at northern India. Ann Med Health Sci Res 4:S73-S78

105. Ahammad ZS, Sreekrishnan TR, Hands CL, Knapp CW, Graham DW (2014) Increased waterborne blaNDM-1 resistance gene abundances associated with seasonal human pilgrimages to the upper Ganges river. Environ Sci Technol 48:30143020

106. Larsson DG (2014) Pollution from drug manufacturing: review and perspectives. Philos Trans R Soc Lond B Biol Sci 369(1656) doi: 10.1098/ rstb.2013.0571

107. Graham DW, Collignon P, Davies J, Larsson DG, Snape J (2014) Underappreciated role of regionally poor water quality on globally increasing antibiotic resistance. Environ Sci Technol 48:11746-11747

108. Bengtsson-Palme J, Boulund F, Fick J, Kristiansson E, Larsson DG (2014) Shotgun metagenomics reveals a wide array of antibiotic resistance genes and mobile elements in a polluted lake in India. Front Microbiol 5:648

109. Larsson DG, de Pedro C, Paxeus N (2007) Effluent from drug manufactures contains extremely high levels of pharmaceuticals. J Hazard Mater 148:751-755

110. Lubbert C, Lippmann N, Busch T et al (2014) Long-term carriage of Klebsiella pneumoniae carbapenemase-2-producing K. pneumoniae after a large single-center outbreak in Germany. Am J Infect Control 42:376-380

111. Jans B, Daniel Huang TD, Bauraing C et al (2015) Infection due to travel-related carbapenemaseproducing Enterobacteriaceae, a largely underestimated phenomenon in Belgium. Acta Clin Belg 70(3):181-187. doi:10.1179/229533371 5Y.0000000001

112. Osterblad M, Kirveskari J, Hakanen AJ, Tissari P, Vaara M, Jalava J (2012) Carbapenemase-producing Enterobacteriaceae in Finland: the first years (2008-11). J Antimicrob Chemother 67:2860 2864

113. Kocsis E, Savio C, Piccoli M, Cornaglia G, Mazzariol A (2013) Klebsiella pneumoniae harbouring OXA-48 carbapenemase in a Libyan refugee in Italy. Clin Microbiol Infect 19:E409-E411

114. Schubert S (2014) Identifizierung von Antibiotika in urbanen Abwassersystem - Akkumulation an Sediment und Klärschlamm. Präv Gesundheitsfr 9:171-174

115. Rijksinstitut voor Volksgezondheid en Milieu (2011) Veelgestelde vragen ESBL. http://www. rivm.nl/Documenten_en_publicaties/Algemeen Actueel/Veelgestelde vragen/Infectieziekten/Veelgestelde_vragen_ESBL. Zugegriffen: 26 . Okt. 2014.

116. Bundesinstitut für Risikobwertung (2015) Fragen und Antworten zu ESBL- und/oder AmpC-bildenden antibiotikaresistenten Keimen; Aktualisiere FAQ vom 19.01.2015. http://www.bfr.bund.de/ $\mathrm{cm} / 343$ /fragen-und-antworten-zu-esbl-und-ampc-bildenden-antibiotikaresistenten-keimen.pdf. Zugegriffen: 8. Juni 2015

117. Yahav D, Farbman L, Leibovici L, Paul M (2012) Colistin: new lessons on an old antibiotic. Clin Microbiol Infect 18:18-29

118. Livermore DM (2012) Current epidemiology and growing resistance of gram-negative pathogens. Korean J Intern Med 27:128-142 
119. Canton R, Akova M, Carmeli Y et al (2012) Rapid evolution and spread of carbapenemases among Enterobacteriaceae in Europe. Clin Microbiol Infect 18:413-431

120. Karageorgopoulos DE, Wang $R, Y u X H$, Falagas ME (2012) Fosfomycin: evaluation of the published evidence on the emergence of antimicrobial resistance in gram-negative pathogens. J Antimicrob Chemother 67:255-268

121. Falagas ME, Grammatikos AP, Michalopoulos $A$ (2008) Potential of old-generation antibiotics to address current need for new antibiotics. Expert Rev Anti Infect Ther 6:593-600

122. Livermore DM, Warner M, Mushtaq S, Doumith M, Zhang J, Woodford N (2011) What remains against carbapenem-resistant enterobacteriaceae? Evaluation of chloramphenicol, ciprofloxacin, colistin, fosfomycin, minocycline, nitrofurantoin, temocillin and tigecycline. Int J Antimicrob Agents 37:415-419

123. Oostdijk EA, Smits $L$, de Smet AM, Leverstein-van Hall MA, Kesecioglu J, Bonten MJ (2013) Colistin resistance in gram-negative bacteria during prophylactic topical colistin use in intensive care units. Intensive Care Med 39:653-660

124. Daikos GL, Tsaousi S, Tzouvelekis LS et al (2014) Carbapenemase-producing Klebsiella pneumoniae bloodstream infections: lowering mortality by antibiotic combination schemes and the role of carbapenems. Antimicrob Agents Chemother 58:2322-2328

125. Tumbarello $M$, Viale P, Viscoli C et al (2012) Predictors of mortality in bloodstream infections caused by Klebsiella pneumoniae carbapenemase-producing K. pneumoniae: importance of combination therapy. Clin Infect Dis 55:943-950

126. Durante-Mangoni E, Signoriello G, Andini R et al (2013) Colistin and rifampicin compared with colistin alone for the treatment of serious infections due to extensively drug-resistant Acinetobacter baumannii: a multicenter, randomized clinical trial. Clin Infect Dis 57:349-358

127. Aydemir H, Akduman D, Piskin N et al (2013) Colistin vs. the combination of colistin and rifampicin for the treatment of carbapenem-resistant Acinetobacter baumannii ventilator-associated pneumonia. Epidemiol Infect 141:1214-1222

128. Theuretzbacher $U$ (2012) Pharmacokinetic and pharmacodynamic issues for antimicrobial therapy in patients with cancer. Clin Infect Dis 54:1785-1792

129. Spellberg B (2011) The antibiotic crisis: can we reverse 65 years of failed stewardship? Arch Intern Med 171:1080-1081

130. Federal Drug Administration (2004) Innovation or stagnation: challenge and opportunity on the critical path to new medical products. http:// www.fda.gov/oc/initiatives/criticalpath/whitepaper.html. Zugegriffen: 13. Okt. 2014

131. Idelevich EA, von Eiff C, Friedrich AW et al (2011) In vitro activity against Staphylococcus aureus of a novel antimicrobial agent, PRF-119, a recombinant chimeric bacteriophage endolysin. Antimicrob Agents Chemother 55:4416-4419

132. Weisman LE, Thackray HM, Steinhorn RH et al (2011) A randomized study of a monoclonal antibody (pagibaximab) to prevent staphylococcal sepsis. Pediatrics 128:271-279

133. Romani AA, Baroni MC, Taddei S et al (2013) In vitro activity of novel in silico-developed antimicrobial peptides against a panel of bacterial pathogens. J Pept Sci 19:554-565
134. Roos D, Dijksman LM, Tijssen JG, Gouma DJ, Gerhards MF, Oudemans-van Straaten HM (2013) Systematic review of perioperative selective decontamination of the digestive tract in elective gastrointestinal surgery. Br J Surg 100:15791588

135. de Smet AM, Bonten MJ, Kluytmans JA (2012) For whom should we use selective decontamination of the digestive tract? Curr Opin Infect Dis 25:211-217

136. Daneman N, Sarwar S, Fowler RA, Cuthbertson BH, Su DCSG (2013) Effect of selective decontamination on antimicrobial resistance in intensive care units: a systematic review and meta-analysis. Lancet Infect Dis 13:328-341

137. Sinha B, van Assen S, Friedrich AW (2014) Important issues for perioperative systemic antimicrobial prophylaxis in surgery. Curr Opin Anaesthesiol 27:377-381

138. Huang SS, Septimus E, Kleinman K et al (2013) Targeted versus universal decolonization to prevent ICU infection. N Engl J Med 368:2255-2265

139. Climo MW, Yokoe DS, Warren DK et al (2013) Effect of daily chlorhexidine bathing on hospitalacquired infection. N Engl J Med 368:533-542

140. Derde LP, Cooper BS, Goossens H et al (2014) Interventions to reduce colonisation and transmission of antimicrobial-resistant bacteria in intensive care units: an interrupted time series study and cluster randomised trial. Lancet Infect Dis 14:31-39

141. Schweickert B, Eckmanns T, Bärwolff S, Wischnewski N, Meyer E (2014) Surveillance des Antibiotikaverbrauchs in Krankenhäusern - Aufgaben des öffentlichen Gesundheitsdienstes. Bundesgesundheitsblatt Gesundheitsforschung Gesundheitsschutz 57

142. de With K, Allerberger F, Amann S et al (2013) S3 Leitlinie: Strategien zur Sicherung rationaler Antibiotika-Anwendung im Krankenhaus. AWMF Registernummer 092/001, Version 15. 12. 2013 